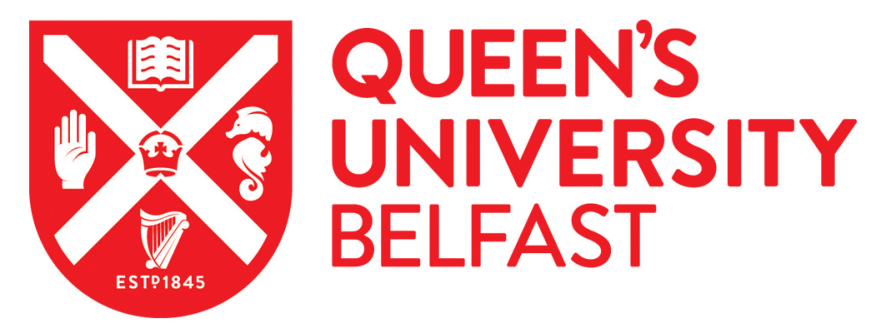

\title{
Vulnerability and psychosocial risk factors regarding people who identify as transgender. A systematic review of the research-evidence.
}

Brown, M., \& Mccann, E. (2017). Vulnerability and psychosocial risk factors regarding people who identify as transgender. A systematic review of the research-evidence. International Journal of Mental Health Nursing, 39(1). https://doi.org/10.1080/01612840.2017.1382623

Published in:

International Journal of Mental Health Nursing

Document Version:

Peer reviewed version

Queen's University Belfast - Research Portal:

Link to publication record in Queen's University Belfast Research Portal

Publisher rights

Copyright ( 2017 Informa UK Limited. This work is made available online in accordance with the publisher's policies. Please refer to any applicable terms of use of the publisher

\section{General rights}

Copyright for the publications made accessible via the Queen's University Belfast Research Portal is retained by the author(s) and / or other copyright owners and it is a condition of accessing these publications that users recognise and abide by the legal requirements associated with these rights.

Take down policy

The Research Portal is Queen's institutional repository that provides access to Queen's research output. Every effort has been made to ensure that content in the Research Portal does not infringe any person's rights, or applicable UK laws. If you discover content in the Research Portal that you believe breaches copyright or violates any law, please contact openaccess@qub.ac.uk. 


\title{
Vulnerability and psychosocial risk factors regarding people who identify as transgender. A systematic review of the research-evidence
}

\begin{abstract}
The aim of this systematic review was to identify the issues related to the vulnerability and psychosocial risk factors of people who identify as transgender. A search of relevant electronic databases from 2007 to 2017 was conducted. Included studies involved transgender people, vulnerability and risk factors. Following the application of rigorous inclusion and exclusion criteria a total of 21 papers were considered suitable for the review. The identified themes included sexual risks, substance use, psychological vulnerability risk factors, Social vulnerability risk factors and protective factors and behaviors. Nurses are in a strong position to address pertinent concerns and to provide the necessary psychosocial supports to this population.
\end{abstract}

\section{Keywords:}

Transgender, Risk, vulnerability, GLBT, Social inclusion 


\section{Vulnerability and psychosocial risk factors regarding people who identify as transgender. A systematic review of the research-evidence}

\section{INTRODUCTION AND BACKGROUND}

Transgender is an 'umbrella' term that relates to people who do not 'fit' with the prevailing gender binary categorisation of male or female. A person's gender identity or expression differs from their birth sex, whereby transwomen were assigned male at birth and transmen have been designated female at birth (Coleman et al., 2011; Wylie et al., 2016). Throughout this paper, the authors have used the term trans* to encapsulate the spectrum of identities and experiences of people whose assigned sex at birth does not match their own feelings of gender identity nor conform to societal gender norms (National LGBT Health Education Center, 2016).

Internationally, there has been an increased interest in the experiences, health and social care requisites of people whom identify as trans* from a human rights and social inclusion perspective (Couch et al., 2007; Baur \& Schiem, 2015; Daniel et al., 2015; Gridley et al., 2016). There have been concerns around different aspects of health and wellbeing among this group, including vulnerability and risk factors, and the potential responses from healthcare providers (Institute of Medicine, 2011). Trans* people can be vulnerable to a range of psychosocial issues including violence, discrimination, financial hardship, drug and alcohol misuse, and issues related to accessing and using appropriate health and social care services (Bockting et al., 2013; Dispenza, Watson, Chung \& Brack, 2012). People who identify as trans* also are at a significantly higher risk of contracting HIV and other sexually transmitted infections, compared to the general population (Chen, McFarland, Thompson \& Raymond, 2011; Reisner, Perkovich \& Mimiaga, 2010). Rates of HIV have become a public health issue with particularly high figures shown among transwomen. Global prevalence rates can vary considerably with 2\% recorded in Pakistan and 43.7\% in India. (Baral et al., 2013). Current United States (US) 
studies reveal that roughly $28 \%$ of trans* people were infected with the human immunodeficiency virus (HIV) and $21 \%$ were infected with other sexually transmitted infections (STIs) (Herbst et al., 2008). Another study showed that 52\% of participants had HIV (Edwards, Fisher \& Reynolds, 2007). These elevated rates may be attributed to high-risk sexual practices including unprotected sex with male partners, injection drug use and sex work (Mimiaga, Reisner, Tinsley, Mayer \& Safren, 2009; Operario, Soma \& Underhill, 2008). Other risk factors include social exclusion, unmet healthcare needs and financial hardship that may explain higher rates of HIV (Pinto, Melendez \& Spector, 2008). Also, the negative experiences associated with stigma and discrimination can lead to exclusion from HIV treatment, support and prevention services (Khan et al. 2008; Bith-Melander, Sheoran \& Sheh, 2010). There is statistically significant evidence linking high rates of depression as a significant risk factor for contracting HIV (Melendez \& Pinto, 2007). Violence, in any form, towards trans* people may be an intermediate factor in the acquisition of HIV (Grant, Mottet \& Tranis, 2011). There is also a higher risk of HIV and other sexually transmitted infections (STIs) due to social factors such as employment discrimination and engagement in sex work (Operario et al., 2008).

The psychological distress experienced by trans* people can be a manifestation of the challenges associated living in an oppressive society and gender-related victimisation (Ellis, Bailey \& McNeil, 2015; Grant et al., 2011). In one study, $87 \%$ of respondents identified discrimination and prejudice events in their lives directly related to their trans* identity (Couch et al., 2007). Globally, there are also significantly higher rates of substance use that has distinct biopsychosocial consequences and therefore, will need specific tailored interventions from practitioners and service providers (Clements-Nolle, Marx, Guzman \& Katz, 2001; De Santis, 2009; Nemoto et al., 2012). To date, the main focus has been on the needs of transmen due to their high rates of alcohol and illicit drug use (Santos et al., 2014). The elevated rates may be attributed to the negative experiences of gender minority stress (Hendricks \& Testa, 2012). A 
significant number of participants in one study $(63 \%)$ described either verbal, physical or sexual victimisation experiences (Operario \& Nemoto, 2005). In one study, transmen were eight times more likely, than those in the general population, to engage in illicit drugs as a way of coping with discrimination (Grant et al., 2011). People may also use drugs and alcohol to deal with the deleterious effects of stigma and victimisation (Fredrikson-Goldsen et al., 2013). Trans* people are twice as likely to be unemployed with increasing numbers of people involved in sex work and concordant substance use (Herbst et al., 2008). There are increasing incidences of depression and associated suicidality (Grant et al., 2011). The available figures reveal that the rates of depression are between $26 \%$ and 66\% (Nemoto, Bodeker \& Iwamoto, 2011; Shipherd, Green \& Abramovitz, 2010 and anxiety was (33\%) (Bockting et al., 2013). Furthermore, alcohol and illicit drug use ranged between 20-36\% (Herbst et al., 2008; Operario \& Nemoto, 2005). The rates for suicidality are between 37-65\% (Liu \& Mustanski, 2012; Nuttbrock et al., 2009).

Despite these concerns, there still remain significant gaps around the health and social care services that are available to trans* people (Grant et al., 2011; Resiner et al., 2016; Wylie et al., 2016). For instance, there is an insufficient range of interventions for HIV and STI treatment, prevention and care (Sullivan et al., 2012). There are also significant shortcomings in knowledge and research into poverty, homelessness and the impact of substance use on the trans* population (Grant et al., 2011). Therefore, this systematic review explored concerns and highlighted pertinent issues related to vulnerability and psychosocial factors relevant to this group.

\section{METHODS}

The focus of the review was peer-reviewed empirical studies that used qualitative, quantitative or mixed research methods that addressed the study aims and review questions. 


\section{Review questions}

1. What are the vulnerability and psychosocial risk factors identified by people who are transgender?

2. What supports, services and treatment options, are required by people who identify as transgender?

\section{Objectives}

- Search for international research studies

- Collect empirical data on the vulnerability and risk experiences of people who identify as transgender

- Critically analyse and compare these findings with the wider legislative, policy and research evidence base

- Inform mental health policy, practice, education, and research.

\section{Settings and participants}

The inclusion criteria were people over 18 years of age whom identified as trans*. Studies that included trans* people as a sub-population of a wider LGBT population were excluded. Only studies that exclusively focused on the trans* population were included.

\section{Search and selection strategy}

A subject Librarian was enlisted to assist with the literature search strategy. The databases used in the search were CINAHL, MEDLINE, PsycINFO and Sociological Abstracts. The search terms used were: transgender* OR transsex* OR gender varian* OR gender dysphoria AND risk OR vulnerab* OR mental health. The data were accessed from October 2007 to October 2017. An example of the search strategy used in one electronic database is shown in Table 1. ***Insert Table 1 here*** 
The searches revealed 1216 hits across all the databases. A flow chart (Figure 1) was used to present the results of the searches (Moher, Liberati, Telzlaff \& Altman, 2009). The inclusion criteria were limited to academic journals, peer reviewed empirical studies, and written in English. The studies had to focus on risk factors and the experiences of adults who identify as transgender. A hand search was also conducted of the reference lists of the identified papers leaving a total of 21 papers for the review.

*** Insert Figure 1 here***

\section{Quality assessment}

A recognized quality assessment tool was used as an evidence-based framework to review the papers (Critical Appraisal Skills Programme, 2013). Specific questions were consistently applied to each of the selected studies (see Table 2). Each question was scored zero, one or two out of a possible score of 20 points. A score of zero was assigned if the paper contained no information, one if there was a moderate amount, and a score of two indicated that the question was fully addressed (Rushbrooke, Murray \& Townsend, 2014). A total of 13 studies achieved a score of 17 or greater, indicating good quality information (Benotsch, Zimmerman, Cathers \& McNulty, 2016; Boza \& Perry, 2014; de Bolger, Jones, Dunstan \& Lykins, 2014; Horvath, Iantaffi, Romine \& Bockting, 2014; Kaplan et al., 2015; Keuroghlian, Reisner, White \& Weiss, 2015; Marshall et al., 2016; Nuttbrock et al., 2015; Reback, Shoptaw \& Downing, 2012; Reisner et al., 2010; Rotondi et al., 2011; Scheim, Bauer \& Shokoohi, 2017; Taylor, Bimbi, Joseph, Margolis \& Parsons, 2011). A score of between 14 and 16 was given to 6 studies that showed that there were information gaps related to clarity of the aims, data collection methods, research relationships considered and ethics statements (Benotsch, Zimmerman, Cathers \& McNulty, 2013; Dadasovich et al., 2017 ; Reisner et al. 2010; Reisner, White, Mayer \& Mimiaga, 2014; Testa et al., 2012; Wilson, Arayasirikul \& Johnson, 2013). Finally, 2 studies recorded scores of 13 and less and this was due to the availability of limited information around the aims, ethics and the consideration of research relationships (Edwards et al., 2007; Sanchez, 
Finlayson, Murrill, Guilin \& Dean, 2010). All of the studies addressed the objectives of the review and therefore were deemed suitable for inclusion.

\section{$* * *$ Insert Table 2 here $* * *$}

\section{Characteristics of the selected studies}

The 21 studies that addressed the study aim and objectives are presented in Table 3 . The majority of studies $(n=15)$ were conducted in the United States (US). The remainder were carried out in Australia $(n=2)$, Argentina $(n=1)$, Canada $(n=2)$ and Lebanon $(n=1)$. Sample sizes ranged from 10 to 1229 study participants involving people whom identify as transgender. All of the studies considered in the review used a selection of data collection methods that included surveys, questionnaires and interviews. A total of sixteen studies were quantitative, adopting a range of measures and survey approaches, two papers used qualitative approaches and adopted interviews and two papers utilized a mixed method design by way of interviews and a survey.

\section{***Insert Table 3 here ***}

\section{Data extraction and analysis}

The review process was guided by recognized methods involving the synthesis of mixed literature (Mays, Pope \& Popay, 2005). A thematic analysis of the data was undertaken. All of the emergent themes were systematically identified across all the studies and coded. They were grouped into concepts to allow for contrasts and comparisons to be made between themes and studies. The emergent themes were identified independently and then discussed, verified and agreed by the reviewers (Caldwell, Henshaw \& Taylor, 2011).

\section{RESULTS}

Following a critical analysis of the studies, five key themes were identified:

(i) Sexual risk and risk-taking behaviors; (ii) substance use; (iii) psychological vulnerability risk factors; (iv) social vulnerability risk factors; and (v) protective factors and behaviors. 


\section{Sexual risk and risk-taking behaviors}

Worldwide, HIV among transwomen is estimated to be almost fifty times higher than the general population (Edward et al., 2007, Nuttbrock et al., 2015). In the United States (US), studies have shown consistently higher rates of HIV and STIs in the trans* population. In the current review, figures range between $26-44 \%$ compared with the general population (Reisner et al., 2010; Reisner et al., 2014). Where HIV care and supports are concerned, survival rates for transwomen were less than 50\%. There was often a poor uptake of services with the contributing factors including stigma, distrust, confidentiality issues and poor location and access issues (Wilson et al., 2013). In another study, psychosocial stressors such as unsafe sex and stressful life events were identified as challenges for transwomen (Sanchez et al., 2010). Other studies identified having multiple sex partners, engaging in sex work and high incidences of the non-use or inconsistent use of condoms, as significantly increasing the risk of HIV and other STIs (Reisner et al., 2010; Sanchez et al., 2010). Furthermore, research involving transmen who have sex with men has shown a significant elevated level of risk for HIV and STIs with almost $44 \%$ of participants reporting unprotected sexual activity (Reisner et al., 2010). As well as the physical risks associated with the topic, psychological risks are evident in the research. For instance, in gender abuse among transwomen, one study discovered associations between unprotected receptive anal intercourse and casual or 'commercial' sexual partners and higher HIV incidences. This may, in part, be due to trans* women seeking out sexual relationships for emotional support as a maladaptive coping response (Nuttbrock et al., 2015). Scheim et al., (2017) identified an association between a history of transphobic assault and greater drug use in people who are transgender. Additionally, in the same sample, sex work was also correlated with greater drug use within the trans* population. In another study undertaken in California, findings suggest that the use of testosterone was associated with an increase in transmen's sexual activity with men who have sex with other men. The reported 
increase in sexual activity with partners from populations with high HIV prevalence may have important risk-taking prevention implications for transmen (Dadasovich et al. 2017).

Some studies revealed helpful HIV reduction interventions such as the Girlfriend project consisting of group support sessions. The study results demonstrated that participants had fewer sexual partners and less unprotected sex following their positive experiences of the group (Taylor et al., 2011). Appropriate safety considerations were identified that included social, emotional, physical, sexual and financial aspects (Kaplan et al., 2015). Internet dating was also seen as a potentially useful HIV prevention intervention by targeting trans* people at high risk of HIV infection (Benotsch et al., 2016).

\section{Substance use}

Compared to the general population, there is an increased prevalence of substance use among people who identify as trans* (Keuroghlian et al., 2015). There are significant gaps in the available evidence-base and it is only recently that researchers have become more interested in substance use and the associated risks among trans* groups (Benotsch et al., 2013; Hovarth et al., 2014). Positive correlations have been discovered between substance use disorders (SUDs) and demographics, gender identity issues and mental health concerns (Keuroghlian et al., 2015). Furthermore, there has been a significant rise in the non-medical use of prescription drugs (NMUPD) that has led to increased public health concerns and a demonstrable rise in the rates of depression and anxiety due to this phenomenon (Zullig \& Divin, 2012). The common non-prescription drugs being used illicitly are stimulants, 'downers' and analgesics (Keuroghlian et al., 2015). Individuals may self-medicate as a means of coping with the psychosocial stressors that people who identify as trans* endure in their daily lives including depression, anxiety, social isolation and loneliness (Benotsch et al., 2013). High levels of marijuana use, alcohol misuse and significantly elevated incidences of unprotected sex in transwomen, may increase the risks of HIV and other STIs (Hovarth et al., 2014). One in four 
transmen who participated in one study, had engaged in 'risky sex' associated with alcohol use, compounded by other psychosocial issues such as depression, anxiety and victimization experiences (Reisner et al., 2014). It is recognized that trans people who are prescribed medication for depression and other mental health conditions may be susceptible to using other non-prescription or recreational drugs. The use of poly-substances, including alcohol, can lead to multiple mental and physical health problems (Benotsch et al., 2013). Another common issue in the studies was the non-medical use of hormones. The main public health concerns are related to how the hormones are procured, their safe administration, and the potential risk of infections and complications. Evidence suggests that the use of medically prescribed hormones is positively co-related with better quality of life outcomes for trans people (Benotsch et al., 2013). In a 2017 study carried out in Ontario, cocaine and amphetamine use was higher when compared with the non-trans* population (Scheim et al., 2017).

\section{Psychological vulnerability risk factors}

There are high incidences of mental health issues related to the myriad of psychosocial issues faced by people who identify as transgender. There are significantly high recorded statistics related to suicidal ideation, suicide plans and suicide attempts. The prevalence rates for attempted suicide are $32 \%$ and 33\% respectively (Marshall et al., 2016). Furthermore, internalized stigma has been strongly associated with suicidality (Marshall et al., 2016). Current rates for depression among trans* people stands at $21-60 \%$ and reflects the impact of the challenges faced by people (Boza \& Perry, 2014). Conversely sexual satisfaction was perceived by many study participants as a protective factor against poor mental health (Rotondi

et al., 2011). However, transphobic experiences such as stigma, violence and victimization were found to be particularly damaging to a person's mental health and well-being (Rotondi et al., 2011). There were strong correlations between physical and sexual violence and increased 
suicide attempts (Testa et al., 2012). Greater social supports were equated with lower levels of depressive symptoms (Boza \& Perry, 2014). Furthermore, there were improvements in overall mental health following the process of transition (de Bolger et al., 2014).

People who identify as trans* can experience the damaging effects of victimization with $70 \%$ of participants in one study reporting at least one instance of gender-related victimization (Boza $\&$ Perry, 2014). The negative reaction of society to a person's gender identity can have a profound effect on the person. Transphobia, stigma and discriminatory attitudes can lead to social isolation, depression, anxiety and other mental health conditions (Marshall et al., 2016). One study that specifically investigated the potentially traumatic psychological effects of physical and sexual violence towards trans* people. The results identified that both transmen and transwomen who experienced violence had a significantly higher risk of suicidal ideation, suicide attempts and substance abuse. Key violent offenders were in polarized positions in that they were either complete strangers or members of the trans person's family, including partners. Only $10 \%$ of victims reported the attack to the police authorities (Testa et al., 2012).

\section{Social vulnerability risk factors}

People who identify as trans* often have challenges in the work environment that can make working untenable. Trans people can face discriminatory experiences in the workplace that can lead to unemployed, despite having key work skills and valuable experience, resulting in economic hardship. Additionally, there can be issues with accessing appropriate quality housing and some trans people can become homeless (Reback et al., 2012). Scheim et al., (2017) identified the issue of homelessness and under-housing as being associated with greater drug use among trans people. Other social stressors may be related to stigma, discrimination and social exclusion. The negative aspects can have a damaging effect on a trans person's value and self-worth. Individuals can be susceptible to isolation and loneliness and subjected to ostracism and rejection, not just by wider society, but also by family members (Boza \& Perry, 
2014). There may be issues around emotional and physical safety. For many, the importance of 'passing' in the new gender-role is crucial in terms of greater confidence and increased selfregard. Also, being recognized as trans* and being accepted is a fundamental part of identity formation and development (Reisner et al., 2010).

Enhanced levels of social support and an expanded social network have been positively corelated with less depressive experiences. There is evidence to suggest that following surgery, trans* people have richer friendships and social relationships, and greater opportunities to have more intimate relationships. People can develop acceptance and higher self-esteem and, as a result, become less socially isolated (Boza \& Perry, 2014). Still, there are barriers to accessing services, for example sexual health services, and culturally appropriate and supportive services. There remains a limited awareness of the specific needs of trans* people and negative attitudes towards trans* people are rampant in society (Sanchez et al., 2010; Testa et al., 2012).

\section{Protective factors and behaviors}

Trans* people face a multitude of challenges that may affect health and well-being. Like all individuals, trans* people have fundamental psychosocial needs that should be recognized, acknowledged and appreciated (Hovarth et al., 2014). Consequently, services need to be responsive, supportive and individually tailored to the distinct needs of the trans* population. Trans* people need access to good housing, employment opportunities, and they need support and protection through legislation and policies that upholds their human rights (de Bolger et al., 2014). From a financial perspective, trans* people need to be supported in claiming welfare benefits, essential during the process of transitioning. Trans* people who had fully medically transitioned, and supported in doing so, had better mental health; they were less prone to anxiety and had fewer symptoms of depression (Rotondi et al., 2011). Also, support in dealing with internalized stigma due to trans* identity and the provision of 'stable' housing was found to be beneficial and protective in addressing lifetime suicidal behaviors. Increased acceptance 
of trans* people by health and social care practitioners and access to counselling and psychotherapy may help to prevent suicide attempts and ameliorate emotional distress (Marshall et al., 2011).

Furthermore, studies involving psychosocial interventions that aim to promote resilience, develop peer support and enhance coping skills, have shown promise in reducing HIV risk behaviors (Reisner et al., 2010; Taylor et al., 2011; Wilson et al., 2013). Access to efficient and effective screening and treatments for HIV and STIs is required (Taylor et al., 2011; Reisner et al., 2014). Another protective and supportive factor is the education and training of health and social care staff on the needs of trans* people. This may involve mental health professionals, health professionals in general, and practitioners involved in the assessment of transgender people who are considering or are going through the medical transitioning experience (Boza \& Perry, 2015; de Bolger et al., 2014). Several of the studies reviewed highlighted the importance of social networks and how governmental and non-statutory organizations can provide the necessary supports to trans* individuals and their family members (Edwards et al., 2007; Hovarth et al., 2014; Reisner et al., 2014).

\section{DISCUSSION}

It has become increasingly clear from this systematic review of the available research literature that trans* people continue to face challenges in relation to vulnerability and risk factors associated with societal discriminatory attitudes and behaviors. People who identify as trans also have difficulties accessing and using appropriate housing, social welfare, health and social care services that need to be responsive to their distinct needs. The relevance and implications of the findings from this systematic review will be presented in relation to mental health policy, practice, education and research.

\section{Legislation and policy implications}

Trans* people have been described as 'one of the most vulnerable and discriminated communities' and subjected to human rights violations, stigma, discrimination, 
marginalization and social exclusion (Lo \& Horton 2016). Furthermore, discriminatory societal reactions can impact negatively upon health and social care provision and access to responsive support services (Hammarberg, 2009). Therefore, legislation needs to be developed, implemented and evaluated that sets out clearly the rights and protections afforded to trans* people, thereby tackling stigma and discrimination towards minority groups (World Health Organisation 2013; Stroumsa 2014). Legislation needs to be fully supported by robust equality and diversity policies that reflects and takes account of the distinct needs of the trans* population.

Policy makers and service providers have a duty to address discrimination and social exclusion in employment, education, and health care. Central to effective policy development is the inclusion of the views, experiences and opinions of trans* people, their friends and families. Policy aimed at improving the lives of trans* people needs to be evidence-based and then fully resourced and implemented to ensure that the supports required to address health needs and reduce the consequences of poor health and minimize barriers to accessing health are in place (Cruz 2014). Therefore, collective and sustained action is required on both legislative and policy fronts to address the issues and concerns related to equality and diversity and stigma and discrimination. This extends to equality of access to universal services available for the whole population and to ones dedicated specifically to trans* people (Grant et al., 2011). Addressing these issues is important given the evidence related to the high levels of both physical and mental ill-health experienced across the trans* communities and the significant barriers related to access to healthcare and other services, further compounded by the discriminatory and stigmatizing attitudes from some healthcare providers (Lavesque et al., 2013; McCann \& Sharek 2016; Bouman et al., 2017). It is therefore necessary when planning services that providers make gender reassignment procedures, such as hormones treatment, surgery and psychological support, fully accessible for trans* people and ensure that financial 
costs are covered by welfare benefits and reimbursed by insurance companies (Wylie et al., 2016).

\section{Practice implications}

There are significant practice implications arising from the evidence presented in this systematic review. People who are trans* are frequent users of all health services and there is an opportunity for practitioners to demonstrate positive values and attitudes that fosters an inclusive and respectful care experience (Agius et al., 2011; Wylie et al., 2016). It is necessary for practitioners to develop knowledge and effective clinical skills in working positively with trans* people. This is important to contribute to reducing and minimizing the impact of stigma and negative attitudes which further marginalizes and excludes trans* people from accessing the help and support they need (Bidell 2017).

The distinct mental health needs of trans* people is a concern that requires attention from practitioners in primary and acute care and those working in mental health services. A significant number of trans* people (78\%), for example, contemplated ending their life (Trans* Equality Network Ireland, 2013). Therefore, practitioners across health services need to be alert to the possibility of mental illness and ensure that there is a strong focus within their assessments and clinical practice to identify and address mental health needs (McCann \& Sharek 2016). To respond appropriately, practitioners in mental health services need to provide adequate and appropriate treatment options and a range of psychosocial supports that enable inclusive practices. There needs to be access to person-centered talking therapy that is effective, such as Cognitive Behavior Therapy (CBT), Dialectical Behavior Therapy (DBT), CA-CBT, psychotherapy, counselling and Eye Movement Desensitization Reprocessing (EMDR) that are trans* affirmative as well as resilience building programs aimed at increasing personal coping skills and capacity (Hunt, 2014; Heck et al., 2015; Reisner et al., 2016; Austin et al., 2017). 
Minority stress is a major issue for many trans* people and has significant implications in terms of both internal and external factors such as internalized transphobia, negative expectations, and nondisclosure and lack of belonging. These are important issues that practitioners need to recognize and address regarding the consequences of mental illness and the need for a strong focus on providing interventions, treatment and supports that reduce suicide rates, with new models of practice being developed that support the development of resilience and coping strategies (Breslow et al., 2015; McCann \& Brown 2017; Testa et al., 2017).

Central to effective clinical practice is the need for comprehensive assessments that informs appropriate treatments, interventions and supports. Practitioners need to be self-aware regarding their own attitudes and values to ensure they actively provide care and support that is affirmative, that is non-judgmental, respectful and inclusive (Fredriksen-Goldsen et al., 2014; Whitman \& Bidell 2014; Kanamori et al., 2017). As an integral part of the provision of care and support, mental health practitioners are in an ideal place to create an environment where trans* people can safely disclose, explore and discuss their concerns, aspirations and hopes. Arising from this is the opportunity for mental health practitioners to adopt a systemic approach by providing wider support to the families and significant others of trans* people, thereby seeking to ensure that their needs are recognized, considered and met, to build coping strategies, acceptance and understanding (Simons et al., 2013; McConnell et al., 2016; McCann \& Brown 2017).

Social isolation and loneliness can be significant issues, particularly for many trans* people, lacking meaningful friendships, access to individual supports and social networks (Pantell et al., 2013; Stewart et al., 2017). Mental health practitioners are well placed to work collaboratively with the trans* communities and partners such as social care providers, housing agencies and homeless organizations to develop community networks and support groups that build a sense of belonging and a sense of identity and community connectedness, vital to 
building resilience and enhancing coping strategies (Brennan-Ing et al., 2014; Johnson \& Amella 2014; Hughes 2016).

The nonmedical use of prescription drugs (NMUPD) has become an increasing public health concern in the United States, with abuse rates rising rapidly since the late 1990s. Yet preventing and reducing prescription drug misuse represents a major challenge (Substance Abuse and Mental Health Services Administration 2016). Practitioners therefore have an opportunity as part of their assessment and treatment models to incorporate a focus on identifying the use of NMPUD. An associated issue that emerged from the current review was the availability and safe administering of hormones. Several clinics in the United States, such as the Callen Lorde Community Center in New York, Fenway Health in Boston, and Howard Brown Health Center in Chicago, have developed Informed Consent Protocols to provide hormone therapy to trans people. Such clinics have specific trans health policies that govern the full range of their transspecific healthcare including HIV testing and prevention services (Keuroghlian et al., 2017). Programs, such as HIV and safe-sex initiatives, should be tailored to individual needs and adequately resourced and supported by knowledgeable and skilled practitioners, conversant with the behaviors and distinct support needs of trans* people (Tang et al., 2016).

\section{Education and training issues}

What has emerged from the review is that support staff need access to professional development opportunities including education and training initiatives (Reisner 2010). These can be aligned to person development plans and work initiatives around equality, diversity and anti-discrimination practices. There needs to be adequate resources made available and time allocated to staff to enable them to undertake the necessary education and training. Vulnerable and marginalised groups, including the trans* population, have a right to protection and the necessary supports within educational settings. There needs to be inclusive educational environments that promotes equality, values diversity and encourages dignity and respect 
where people can develop to their full potential. National and local education policies and legislation must address pertinent issues related to gender identity and expression such as discrimination, harassment and victimisation. In learning environments, reasonable accommodations should be provided for individuals undergoing medical procedures related to gender reassignment. Students should be permitted and supported in updating their personal records to match their gender identity and expression. There needs to be access to available resources in terms of mental and emotional support such as counselling, pastoral and advisory services. Sports clubs should be inclusive in their services to trans* people, ensuring that a person can participate in activities according to their identified gender. There needs be robust and effective complaints procedures to deal with bullying, harassment or discrimination related to a person's gender identity or expression. In the current systematic review, there were no studies identified that focused specifically on the education and training requirements of service providers. Training and awareness raising should be made available to all educational, health and social care staff. Equality, diversity and cultural awareness training should feature more prominently within the health and social care curricula at undergraduate and postgraduate levels (De Bolger et al., 2014). The specific holistic needs of trans* people, their families and carers, should be explicitly identified and become a core component and major focus in practice development programs. Decisions will need to be made about the training content, prospective participants, the delivery and evaluation of the training.

\section{Research implications}

A variety of data collection methods were utilized in the selected studies including surveys, measures, questionnaires and interviews. Most studies explored the health and social care needs of trans* people concentrating on individual experiences, concerns and support requirements. There was only one treatment or intervention evaluation study (Taylor et al. 2011). The sample sizes were generally small and ranged from 10 to 1229 study participants. There were no 
national or international multi-center studies or longitudinal investigations. Most of the studies in the review used cross-sectional convenience sampling at one-off conference events that presents research challenges to conducting more longitudinal studies to identify changes over time. One study demonstrated innovative recruitment techniques called 'seeds and chaining' (Rotondi et al. 2011). Many of the studies were undertaken in the US and there was distinct lack of European, African and Asian research. There was a lack of policy and legislation studies and those focusing on mental health issues. Therefore, opportunities exist to expand the evidence-base around psychological and social interventions their effectiveness and impact on individuals, families and significant others. There is a paucity of research related to education and training involving trans* people, families and health practitioners. There is a need for preand post-test evaluations that may inform future mental health education curricula at undergraduate and postgraduate levels.

\section{Strengths and limitations}

The review has revealed important issues that may affect the lives of people who identify as trans*, their families and others in their social group. The concerns for mental health practitioners around potential supports and interventions have become increasingly apparent. However, in terms of empirical evidence, the review is limited by the paucity of European studies, recruitment challenges and the under-representation of people of color. Future research studies should consider ways of addressing these shortcomings.

\section{CONCLUSION}

There is a growing interest in the health and social care needs of people who identify as trans* and this has become increasingly apparent through the issues that have emerged in this systematic review. The challenge now is for service providers, including mental health practitioners, to work collaboratively with trans* communities to develop and implement effective strategies and interventions that meet the identified requirements. Adequate resources 
must be provided to support and enable future practice development initiatives and the delivery of appropriate services that address equality, diversity and social inclusion issues.

\section{Disclosure of interest:}

The authors report no conflicts of interest. 


\section{REFERENCES}

Austin, A., Craig, S. L., \& Alessi, E. J. (2017). Affirmative Cognitive Behavior Therapy with transgender and gender nonconforming adults. Psychiatric Clinics, 40(1), 141-156.

Baral, S.D., Poteat, T., Stromdahl, S., Wirtz, A.L., Guadamuz, T.E. \& Beyrer, C. (2013) Worldwide burden of HIV in transgender women: A systematic review and meta-analysis. Lancet Infectious Diseases 13:214-222. doi.org/10.1016/S1473-3099(12)70315-8

Baur, G.R. \& Schiem, A.I. (2015) Transgender People in Ontario, Canada: Statistics from the Trans PULSE Project to Inform Human Rights Policy. Ontario: Trans Pulse.

Benotsch, E.G., Zimmerman, R., Cathers, L., \& McNulty, S. (2013) Non-medical use of prescription drugs, polysubstance use, and mental health in transgender adults. Drug and Alcohol Dependence, 132(1-2), 391-394.

Benotsch, E.G., Zimmerman, R., Cathers, L., Heck, T., McNulty, S., Pierce, J., Perrin, P.B. \& Snipes, D.J. (2016) Use of the internet to meet sexual partners, sexual risk behavior and mental health in transgender adults. Archives of Sexual Behavior 45, 597-605.

Bidell M. (2017) The Lesbian, Gay, Bisexual, and Transgender Development of Clinical Skills Scale (LGBT-DOCSS): Establishing a New Interdisciplinary Self-Assessment for Health Providers, Journal of Homosexuality 64(10), 1432-1460.

Bith-Melander, P., Sheoran, B. \& Sheh, L. (2010) Understanding sociocultural and psychological factors affecting transgender people of color in San Francisco. Journal of the Association of Nurses in AIDS Care 21, 207-220. doi.org/10.1016/j.jana.2010.01.008

Bockting, W.O., Miner, M.H., Swinburne Romine, R.E., Hamilton, A. \& Coleman, E. (2013) Stigma, mental health and resilience in an online sample of the US transgender population. American Journal of Public Health, 103(5), 943-951.

Bouman, W. P., Claes, L., Brewin, N., Crawford, J. R., Millet, N., Fernandez-Aranda, F. \& Arcelus, J. (2017). Transgender and anxiety: A comparative study between transgender people and the general population. International Journal of Transgenderism, 18(1), 16-26.

Boza, C. \& Perry K.N. (2014). Gender-related victimization, perceived social support, and predictors of depression among transgender Australians. International Journal of Transgenderism 15(1), 35-52.

Brennan-Ing, M., Seidel, L., Larson, B., \& Karpiak, S. E. (2014) Social care networks and older LGBT adults: Challenges for the future. Journal of Homosexuality, 61(1), 21-52.

Breslow, A. S., Brewster, M. E., Velez, B. L., Wong, S., Geiger, E., \& Soderstrom, B. (2015) Resilience and collective action: Exploring buffers against minority stress for transgender individuals. Psychology of Sexual Orientation and Gender Diversity, 2(3), 253-265. 
Caldwell, K., Henshaw, I. \& Taylor, G. (2011) Developing a framework for critiquing health research: An early evaluation. Nurse Education Today 31(8), 1-7.

doi.org/10.1016/j.nedt.2010.11.025

Chen, S., McFarland, W., Thompson, H.M. \& Raymond, H.F. (2011) Transmen in San

Francisco: What do we know from HIV test site data? AIDS and Behavior 15(3), 659-662.

Clements-Nolle, K., Marx, R., Guzman, R. \& Katz, M. (2001) HIV prevalence, risk behaviours, health care use, and mental health status of transgender persons: implications for public health intervention. American Journal of Public Health 91, 915-921.

Coleman, E., Bockting, W., Botzer, M., Cohen-Kettenis, P., DeCuypere, G., Feldman, J., Fraser, L., Green, J., Knudson, G., Meyer, W. J., Monstrey, S., Adler, R. K., Brown, G. R., Devor, A. H., Ehrbar, R., Ettner, R., Eyler, E., Garofalo, R., Karasic, D. H., Lev, A. I., Mayer, G., Meyer-Bahlburg, H., Hall, B. P., Pfaefflin, F., Rachlin, K., Robinson, B., Schechter, L. S., Tangpricha, V., van Trotsenburg, M., Vitale, A., Winter, S., Whittle, S., Wylie, K. R., \& Zucker, K. (2011) Standards of care for the health of transsexual, transgender, and gender-nonconforming people, version 7. International Journal of Transgenderism 13(4), 165-232.

Couch, M., Pitts, M., Mulcare, H., Croy, S., Mitchell, S. \& Patel, S. (2007) Tranznation: A report on the health and well-being of transgender people in Australia and New Zealand (Series No. 65). Australian Research Centre in Sex, Health and Society. Melbourne, Australia.

Critical Appraisal Skills Programme (2013) Ten questions to help you make sense of qualitative research. Oxford, Critical Appraisal Skills Programme.

Cruz, T. M. (2014) Assessing access to care for transgender and gender nonconforming people: A consideration of diversity in combating discrimination. Social Sciences \& Medicine, 100, 65-73.

Dadasovich, R., Auerswald, C., Minnis, A.M., Raymond, H.F., McFarland, W. \& Wilson, E.C. (2017) Testosterone and sexual risk among transmen: a mixed methods exploratory study. Culture, Health \& Sexuality 19(2), 256-266. doi.org/10.1080/13691058.2016.1216605

Daniel, H., Butkus, R., Tape, T.G., De Long, D.M., Beachy, M.W., Bornstein, S.S. \& Rehman, S.U. (2015) Lesbian, gay, bisexual, and transgender health disparities: Executive summary of a policy position paper from the American College of Physicians. Annals of Internal Medicine 163(2), 135-137.

de Bolger, A., Jones, T., Dunstan, D. \& Lykins, A. (2014) Australian, trans men: Development, sexuality, and mental health. Australian Psychologist 49, 395-402.

De Santis, J.P. (2009) HIV infection risk factors among male-to-female transgender persons: A review of the literature. Journal of the Association of Nurses in AIDS Care 20, 362-372.

Dispenza, F., Watson, L.B., Chung, Y.B. \& Brack, G. (2012) Experience of Career-Related Discrimination for Female-to-Male Transgender Persons: A Qualitative Study. The Career Development Quarterly 60(1), 65-81. 
Edwards, J.W., Fisher, D.G. \& Reynolds, G.L. (2007) Male-to-female transgender and transsexual clients of HIV service programs in Los Angeles County, California. American Journal of Public Health 97(6), 1030-1033.

Ellis, S.J., Bailey, L. \& McNeil, J. (2015) Trans People's Experiences of Mental Health and Gender Identity Services: A UK Study. Journal of Gay and Lesbian Mental Health 19 (1), 420.

Equality and Human Rights Commission (2010) Provision of goods, facilities and services to trans people: Guidance for public authorities in meeting your equality duties and human rights obligations. London: EHRC.

Fredriksen-Goldsen, K.I., Cook-Daniels, L., Kim, H., Erosheva, E.A., Emlet, C.A., Hoy-Ellis C.P., Goldsen, J. \& Muraco, A. (2013) Physical and mental health of transgender older adults: An at-risk and underserved population. The Gerontologist 53, 664-675.

Fredriksen-Goldsen, K. I., Hoy-Ellis, C. P., Goldsen, J., Emlet, C. A. \& Hooyman, N. R. (2014) Creating a vision for the future: Key competencies and strategies for culturally competent practice with lesbian, gay, bisexual, and transgender (LGBT) older adults in the health and human services. Journal of Gerontological Social Work, 57(2-4), 80-107.

Grant, J.M., Mottet, L.A., \& Tanis J. (2011) Injustice at Every Turn: A Report of the National Transgender Discrimination Survey. National Center for Transgender Equality, Washington D.C.

Gridley, S.J., Crouch, J.M., Evans, Y., Eng, W., Antoon, E., Lyapustina, M., SchimmelBristow, A. et al. (2016) Youth and caregiver perspectives on barriers to gender-affirming health care for transgender youth. Journal of Adolescent Health 59, 254-261.

Hammarberg, T., 2009. Human rights and gender identity: Issue Paper. Council of Europe.

Heck, N. C., Croot, L. C., \& Robohm, J. S. (2015) Piloting a psychotherapy group for transgender clients: Description and clinical considerations for practitioners. Professional Psychology: Research and Practice, 46(1), 30.

Hendricks, M.L. \& Testa, R.J. (2012) A conceptual framework for clinical work with transgender and gender nonconforming clients: An adaptation of the Minority Stress Model. Professional Psychology: Research and Practice 43, 460-467.

Herbst, J.H., Jacobs, E.D., Finlayson, T.J., McKleroy, V.S., Neumann, M.S, \& Crepaz, N. (2008) Estimating HIV prevalence and risk behaviors of transgender persons in the United States: A systematic review. AIDS and Behavior, 12(1), 1-17.

Horvath, K.J., Iantaffi, A., Romine, R.S., \& Bockting, W. (2014) A comparison of mental health, substance use, and sexual risk behaviors between rural and non-rural transgender persons. Journal of Homosexuality, DOI: 10.1080/00918369.2014.872502.

Hughes, M. (2016). Loneliness and social support among lesbian, gay, bisexual, transgender and intersex people aged 50 and over. Ageing \& Society, 36(9), 1961-1981. 
Hunt, J. (2014) An initial study of transgender people's experiences of seeking and receiving counselling or psychotherapy in the UK. Counselling \& Psychotherapy Research 14(4), 288296.

Institute of Medicine (2011) The Health of Lesbian, Gay, Bisexual, and Transgender People. Washington, D.C: The National Academies Press.

Johnson, M. J. \& Amella, E. J. (2014) Isolation of lesbian, gay, bisexual and transgender youth: A dimensional concept analysis. Journal of Advanced Nursing, 70(3), 523-532.

Kanamori, Y., Cornelius-White, J. H., Pegors, T. K., Daniel, T., \& Hulgus, J. (2017) Development and validation of the transgender attitudes and beliefs scale. Archives of Sexual Behavior, 46(5), 1503-1515.

Kaplan, R.L., Wagner, G.J., Nehme, S., Aunon, F., Khouri, D. \& Mokhbat, J. (2015) Forms of safety and their impact on health: An exploration of HIV/AIDS-related risk and resilience among trans women in Lebanon. Health Care Women International 36(8), 917-935. doi.org/10.1080/07399332.2014.896012

Khan, S.I., Hussain, M.I., Gourab, G., Parveen, S., Bhuiyan, M.I. \& Sikder, J. (2008) Not to sigmatize but to humanize sexual lives of the transgender population (hijra) in Bangladesh: Condom chat in the AIDS era. Journal of LGBT Health Research 4, 127-141.

Keuroghlian, A.S., Reisner, S.L, White, J.M. \& Weiss, R.D. (2015) Substance use and treatment of substance use disorders in a community sample of transgender adults. Drug and Alcohol Dependence 152, 139-146.

Keuroghlian, A. S., Ard, K. L., \& Makadon, H. J. (2017) Advancing health equity for lesbian, gay, bisexual and transgender (LGBT) people through sexual health education and LGBTaffirming health care environments. Sexual Health, 14(1), 119-122.

Lavesque, J., Harris, M. \& Russell, G. (2013) Patient-centred access to health care: Conceptualising access at the interface of health systems and populations. International Journal of Equality in Health 12, 16-28.

Liu, R.T. \& Mustanski, B. (2012) Suicidal ideation and self-harm in lesbian, gay, bisexual, and transgender youth. American Journal of Preventive Medicine, 42(3), 21-228.

Lo, S., \& Horton, R. (2016). Transgender health: An opportunity for global health equity. The Lancet, 388(10042), 316-318.

Marshall, B.D.L., Socias, M.E., Thomas, T., Zalazar, V., Sued, O. \& Aristegui, I. (2016) Prevalence and correlates of lifetime suicide attempts among transgender persons in Argentina. Journal of Homosexuality 63(7), 955-967.

Mays, N., Pope, C. \& Popay, J. (2005) Systematically reviewing qualitative and quantitative evidence to inform management and policy-making in the health field. Journal of Health Services Research and Policy 10 (Suppl. 1), 6-20. 
McCann, E., \& Sharek, D. (2016) Mental health needs of people who identify as transgender: A review of the literature. Archives of Psychiatric Nursing, 30(2), 280-285.

McCann, E., \& Brown, M. (2017) Discrimination and resilience and the needs of people who identify as Transgender: A narrative review of quantitative research studies. Journal of Clinical Nursing, DOI: 10.1111/jocn.1391.

McConnell, E. A., Birkett, M. \& Mustanski, B. (2016) Families matter: Social support and mental health trajectories among lesbian, gay, bisexual, and transgender youth. Journal of Adolescent Health, 59(6), 674-680.

Melendez, R.M. \& Pinto, R. (2007) It's really a hard life: Love, gender and HIV risk among male-to-female transgender persons. Culture, Health and Sexuality 9, 233-245.

Mimiaga, M. J., Reisner, S. L., Tinsley, J. P., Mayer, K. H. \& Safren, S. A. (2009) Street workers and internet escorts: Contextual and psychosocial factors surrounding HIV risk behavior among men who engage in sex work with other men. Journal of Urban Health 86, 54-66.

Moher, D., Liberati A, Tetzlaff J, Altman DG, The PRISMA Group (2009). Preferred Reporting Items for Systematic Reviews and Meta-Analyses: The PRISMA Statement. PLoS Med 6 (6): e1000097. doi:10.1371/journal.pmed1000097).

National LGBT Health Education Center (2016) Affirmative Care for Transgender and Gender Non-Conforming People: Best Practices for Front-line Health Care Staff. Boston MA: The Fenway Institute.

Nemoto, T., Bodeker, B. \& Iwamoto, M. (2011) Social support, exposure to violence and transphobia, and correlates for depression among male-to-female transgender women with a history of sex work. American Journal of Public Health 101, 1980-1988.

Nemoto, T., Iwamoto, M., Perngparn, U., Areesantichai, C., Kamitani, E. \& Sakata, M. (2012) HIV-related behaviors among kathoey (male-to-female transgender) sex workers in Bangkok, Thailand. AIDS Care 24, 210-219.

Nuttbrock, L.A., Bockting, W.O., Hwahng, S., Rosenblum, A., Mason, M., Macri, M., \& Becker, J. (2009) Gender identity affirmation among male-to-female transgender persons: A life course analysis across types of relationships and cultural/lifestyle factors. Sexual and Relationship Therapy, 24(2), 108-125.

Nuttbrock, L.A., Bockting, W.O., Rosenblum, A., Hwahng, S., Mason, M., Macri, M., \& Becker, J. (2015) Gender abuse and incident HIV/STI among transgender women in New York City: Buffering effect of involvement in a transgender community. AIDS Behavior 19, 1446-1453.

Operario, D. \& Nemoto, T. (2005) Sexual risk behaviour and substance use among a sample of Asian Pacific Islander transgendered women. AIDS Education and prevention 17, 430443. 
Operario, D., Soma, T. \& Underhill, K. (2008) Sex work and HIV status among transgender women: Systematic review and meta-analysis. Journal of Acquired Immune Deficiency Syndromes 48, 97-103.

Pantell, M., Rehkopf, D., Jutte, D., Syme, S. L., Balmes, J. \& Adler, N. (2013) Social isolation: a predictor of mortality comparable to traditional clinical risk factors. American Journal of Public Health, 103(11), 2056-2062.

Pinto, R.M., Melendez, R.M. \& Spector, A.Y. (2008) Male-to-female transgender individuals building social support and capital from within a gender-focused network. Journal of Gay and Lesbian Social Services 20, 203-220. doi.org/10.1080/10538720802235179

Reback, C.J., Shoptaw, S. and Downing, M.J. (2012) Prevention case management improves socioeconomic standing and reduces symptoms of psychological and emotional distress among transgender women. AIDS Care 24(9), 1136-1144.

Reisner, S.L., Perkovich, B. \& Mimiaga, M.J. (2010) A mixed methods stud y of the sexual health needs of New England transmen who have sex with non-transgender men. AIDS Patient Care and STDs 24(8), 501-513.

Reisner, S.L., White, J.M., Mayer, K.H. \& Mimiaga, M.J. (2014) Sexual risk behaviors and psychosocial health concerns of female-to-male transgender men screening for STDs at an urban community health center. AIDS Care 26(7), 857-864.

Reisner, S.L.; Poteat, T., Keatley, J., Cabral, M., Mothopeng, T., Dunham, E., Holland, C.E., Max, R. \& Baral, S.D. (2016) Global health burden and needs of transgender populations: A review. Lancet 388(10042): 412-414.

Rotondi, N., Bauer, G., Scanlon, K., Kaay, M., Travers, R., \& Travers, A. (2011) Prevalence of and risk and protective factors for depression in female-to-male transgender Ontarians: Trans PULSE project. Canadian Journal of Community Mental Health, 30(2), 135-155.

Rushbrooke, E., Murray, C. and Townsend, S. (2014) The experiences of intimate relationships by people with intellectual disabilities: A qualitative study. Journal of Applied Research in Intellectual Disabilities 27, 531-541.

Sanchez, T., Finlayson, T., Murrill, C., Guilin, V. \& Dean, L. (2010) Risk behaviors and psychosocial stressors in New York City House Ball Community: A comparison of men and transgender women who have sex with men. AIDS Behavior 14, 351-358.

Santos, G.M., Rapues, J., Wilson, E.C., Macias, O., Packer, T., Colfax, G. and Raymond, H.F. (2014) Alcohol and substance use among transgender women in San Francisco: prevalence and association with human immunodeficiency virus infection. Drug and Alcohol Review 33(3), 287-295.

Scheim, A.I., Bauer, G.R. and Shokoohi, M. (2017) Drug use among transgender people in Ontario, Canada: disparities and associations with social exclusion. Addictive behaviors 72 , 151-158. 
Shipherd, J.C., Green, K.E., \& Abramovitz, S. (2010) Transgender clients: Identifying and minimizing barriers to mental health treatment. Journal of Gay and Lesbian Mental Health, 14(2), 94-108. doi.org/10.1080/19359701003622875

Stewart, L., O'Halloran, P., \& Oates, J. (2017) Investigating the social integration and wellbeing of transgender individuals: A meta-synthesis. International Journal of Transgenderism, 1-13.

Stroumsa, D. (2014) The state of transgender health care: Policy, law, and medical frameworks. American Journal of Public Health, 104(3), e31-e38.

Sullivan, P.S., Carballo-Diéguez, A., Coates, T., Goodreau, S.M., McGowan, I., Sanders, E.J., Smith, A., Goswami, P. \& Sanchez, J. (2012) Successes and challenges of HIV prevention in men who have sex with men. The Lancet 380(9839), 388-399.

Taylor, R.D., Bimbi, D.S., Joseph, H.A., Margolis, A.D. \& Parsons, J.T. (2011) Girlfriends: Evaluation of an HIV-risk reduction intervention for adult transgender women. AIDS Education and Prevention 23(5), 469-478.

Testa, R.J., Sciacca, L.M., Wang, F., Hendricks, M.L., Goldblum, P., Bradford, J. \& Bongar, B. (2012) Effects of violence on transgender people. Professional Psychology: Research and Practice 43(5), 452-459.

Testa, R. J., Michaels, M. S., Bliss, W., Rogers, M. L., Balsam, K. F., \& Joiner, T. (2017) Suicidal ideation in transgender people: Gender minority stress and interpersonal theory factors. Journal of Abnormal Psychology, 126(1), 125-136.

Whitman, J. S., \& Bidell, M. P. (2014). Affirmative lesbian, gay, and bisexual counselor education and religious beliefs: How do we bridge the gap?. Journal of Counseling \& Development, 92(2), 162-169.

Wilson, E.C., Arayasirikul, S. \& Johnson, K. (2013) Access to HIV care and support services for African Transwomen living with HIV. International Journal of Transgenderism 14(4), 182-195. doi.org/10.1080/15532739.2014.890090

Wylie, K., Knudson, G., Khan, S.I., Bonierbale, M., Watanyusakul, S. \& Baral, S. (2016) Serving transgender people: Clinical care considerations and service delivery models in transgender health. Lancet 388(10042), 401-411. doi.org/10.1016/S0140-6736(16)00682-6

Zullig, K.J. \& Divin, A.L. (2012) The association between non-medical prescription drug use, depressive symptoms, and suicidality among college students. Addictive Behaviors 37, 890-899. doi.org/10.1016/j.addbeh.2012.02.008 
